\title{
Kajian Daur Hidup (Life Cycle Assessment) dalam Produksi Pupuk Urea: Studi Kasus PT Pupuk Kujang
}

\author{
Joni Safaat Adiansyah¹, Naliawati Prastiya Ningrum² ${ }^{2}$ Dyan Pratiwi², dan Hadiyanto³
}

1Fakultas Teknik, Universitas Muhammadiyah Mataram; e-mail: joni.adiansyah@gmail.com

2Divisi Lingkungan Hidup, Departemen K3LH, PT Pupuk Kujang

${ }^{3}$ Program Studi Ilmu Lingkungan, Sekolah Pascasarjana, Universitas Diponegoro, Semarang

\begin{abstract}
ABSTRAK
Pupuk urea adalah merupakan salah satu jenis pupuk yang paling banyak digunakan oleh petani di Indonesia. Total penggunaan pupuk urea selama tahun 2018 yang tercatat pada Kementerian Perindustrian Indonesia adalah sejumlah 6,27 Juta ton atau mengalami peningkatan 5\% dari tahun sebelumnya. Salah satu pabrik yang menghasilkan pupuk urea adalah PT Pupuk Kujang di Cikampek Jawa Barat. Tujuan dari studi ini adalah untuk mengidentifikasi dampak lingkungan potensial yang dihasilkan dari produksi $50 \mathrm{Kg}$ pupuk urea. Metode yang digunakan dalam kajian dampak daur hidup (Life Cycle Impact Assessment) adalah CML-IA dengan 11 (sebelas) parameter yaitu abiotic depletion dan abiotic depletion (fossil fuel), global warming (GWP100), ozone layer depletion, human toxicity, fresh water dan marine aquatic ecotoxicity, terrestrial ecotoxicity, photochemical oxidation, acidification, dan eutrophication, Adapun batasan sistem menggunakan cradle to grave yang memperhitungakn bahan dasar, proses produksi, transportasi dan pengelolaan limbah (karung bekas pupuk). Dari hasil analisa didapatkan bahwa proses produksi memberikan kontribusi dampak paling besar dibandingkan dengan pengelolaan limbah sisa karung (landfill). Proses produksi memberikan kontribusi terhadap dampak potensial lingkungan pada kisaran 99,14 - 100 persen dari total dampak yang di hasilkan. Sebagai tambahan bahwa dampak yang ditimbulkan pada proses di pabrik ammonia akan memberikan kontribusi lebih besar pada kisaran 22-37 persen lebih besar dibandingkan dengan proses di pabrik urea. Dari hasil analisa dengan memanfaatkan grafik jaringan (networking graph) pada program SimaPro juga menunjukkan bahwa environmental hotspots dari daur hidup pupuk urea disebabkan oleh penggunaan gas alam, katalis molybdenum, penggunaan listrik dari Perusahaan Listrik Negara (PLN), penggunaan polypropylene dalam material karung, dan transportasi. Dengan mempertimbangan environmental hotspot maka tindakan perbaikan berkelanjutan perlu dilakukan baik berupa audit energi maupun pengelolaan penggunaan katalis.
\end{abstract}

Kata kunci: Kajian Daur Hidup, Kajian Dampak, Pupuk, Urea, Dampak Potensial, Produksi, Transportasi, Pupuk Kujang

\begin{abstract}
Urea fertilizer is one of fertilizers that commonly used by the farmer in Indonesia. Based on the data recorded by the Industrial Ministry of Indonesia, total of urea fertilizer that utilized during 2018 was 6.27 Million tons or increase $5 \%$ from the previous year. One of the urea fertilizer plants is PT Pupuk Kujang at Cikampek West Java. The aim of this study is identifying the potential environmental impact that generated from $50 \mathrm{~kg}$ urea fertilizer production. The method of Life Cycle Assessment that applied is CML_IA with 11 (eleven) parameters as follows abiotic depletion dan abiotic depletion (fossil fuel), global warming (GWP100), ozone layer depletion, human toxicity, fresh water dan marine aquatic ecotoxicity, terrestrial ecotoxicity, photochemical oxidation, acidification, dan eutrophication. The system boundary referred to cradle to grave by covering raw material, process production, transportation, and waste management. The analysis result showed that the process production contributed to the environmental potential impact approximately $99.14-100$ percent of total impact generated. In addition, the impact generated of process in ammonia plant was 22-37 percent higher compared to the urea plant production process. The analysis using networking graph in SimaPro software also indicated that environmental hotspots from the life cycle of urea fertilizer were mainly caused by the consumption of natural gas, molybdenum catalyst, utilization of PLN electricity, polypropylene content in fertilizer packaging, and transportation. Considering those environmental hotspots, the continuous improvement by conducting both energy audit and catalyst management usage should be implemented.
\end{abstract}

Keywords: Life Cycle Assessment, Impact Assessment, Fertilizer, Urea, Potential Impact, Production, Transportation, Pupuk Kujang

Citation: Adiansyah, J.S., Ningrum, N.P., dan Pratiwi, D. (2018). Kajian Daur Hidup (Life Cycle Assessment) dalam Produksi Pupuk Urea: Studi Kasus PT Pupuk Kujang. Jurnal Ilmu Lingkungan, 17(3), 522-527, doi:10.14710/jil.17.3.522-527

\section{Pendahuluan}

Pupuk merupakan salah satu kebutuhan utama bagi para petani di seluruh dunia. Penggunaan pupuk 522 sebagai nutrisi tanaman dibutuhkan untuk membantu meningkatkan reproduksi, pertumbuhan, dan produksi (Firmansyah and Syakir 2017). Dalam data 
yang dikeluarkan oleh Food and Agriculture Organization (FAO) terlihat bahwa total konsumsi dunia terhadap tiga nutrisi pupuk yaitu Nitrogen $(\mathrm{N})$, Fosfor $\left(\mathrm{P}_{2} \mathrm{O}_{5}\right)$, dan Kalium $\left(\mathrm{K}_{2} \mathrm{O}\right)$ selama tahun 2016 mencapai 186,67 juta ton (FAO 2017). Diperkirakan kebutuhan akan pupuk NPK meningkat sebesar 6,9\% pada tahun 2020. Peningkatan penggunaan pupuk juga tercatat oleh Kementerian Perindustrian, dimana jumlah penggunaan pupuk NPK selama tahun 2018 sebesar 2,80 juta ton atau naik 7,9\% dibandingkan tahun sebelumnya sedangkan penggunaan pupuk urea tercatat sebesar 6,27 juta ton atau naik 5\% dari tahun sebelumnya (Kemenperin 2019).

Produksi pupuk dalam jumlah yang besar tentu akan memberikan dampak terhadap lingkungan baik yang berasal dari proses produksi maupun distribusinya. Beberapa dampak lingkungan yang mungkin timbul dari proses produksi antar lain peningkatan gas rumah kaca yang dihasilkan dari emisi pembangkit listrik, pencemaran air dari hasil buangan pengolahan air limbah, dan peningkatan konsentrasi debu (Particulate Matter) dari proses pengemasan pupuk.

Pengelolaan dampak lingkungan yang efektif dapat dilakukan dengan mengetahui sumber dampak (environmental hotspot) dan daur hidup dari sebuah proses. Penggunaan kajian daur hidup (life cycle assessment) dalam mengindentikasi dampak sebuah proses telah dilakukan secara luas di seluruh dunia. (Hasler et al. 2015) melakukan kajian daur hidup untuk membandingkan dampak lingkungan dari berbagai macam jenis pupuk, dimana kategori dampak yang dikaji meliputi perubahan iklim, asidifikasi, eutropikasi, pengurangan bahan bakar fosil dan sumber daya. Metode cradle to field digunakan dengan batasan sistem mulai dari material dasar, produksi pupuk, transportasi dan penyimpanan, dan aplikasi pupuk di lapangan. Hasil analisa menunjukkan bahwa proses produksi pupuk memberikan kontribusi terbesar terhadap kategori dampak perubahan iklim, pengurangan bahan bakar fosil, dan asidifikasi (Hasler et al. 2015). Beberapa studi kajian daur hidup (LCA) mengkaji penggunaan pupuk pada produksi kopi (Vera-Acevedo, VélezHenao, and Marulanda-Grisales 2016), jagung dan kedelai (Romeiko 2019). Selain itu, (Quiros et al. 2015) melakukan kajian daur hidup (LCA) dengan menampilkan 3 (tiga) scenario perlakuan pupuk yang berbeda terhadap bunga kol dan tomat. Salah satu kesimpulan dari penelitian yang dilakukan oleh (Skowroñska and Filipek 2014) menyatakan bahwa kajian daur hidup (LCA) adalah merupakan pendekatan untuk identifikasi, kuantifikasi, dan evaluasi terhadap dampak potensial total dari proses pengadaan material dasar ke produksi dan penggunaan hingga pembuangan akhir (grave). Saat ini belum banyak studi kajian daur hidup (LCA) yang berasal dari Pabrik Pupuk.

PT Pupuk Kujang selaku salah satu produsen pupuk di Indonesia memlikili komitmen untuk melakukan proses produksi dan distribusi yang efisien baik dari pertimbangan biaya produksi maupun dampak lingkungan. Salah satu upaya yang dilakukan adalah dengan melakukan kajian daur hidup (LCA) terhadap proses produksi, transportasi, dan pembuangan akhir. Studi ini ditujukan untuk melakukan identifikasi dampak potensial lingkungan dan environmental hotspot dari proses produksi pupuk urea di PT Pupuk Kujang Cikampek.

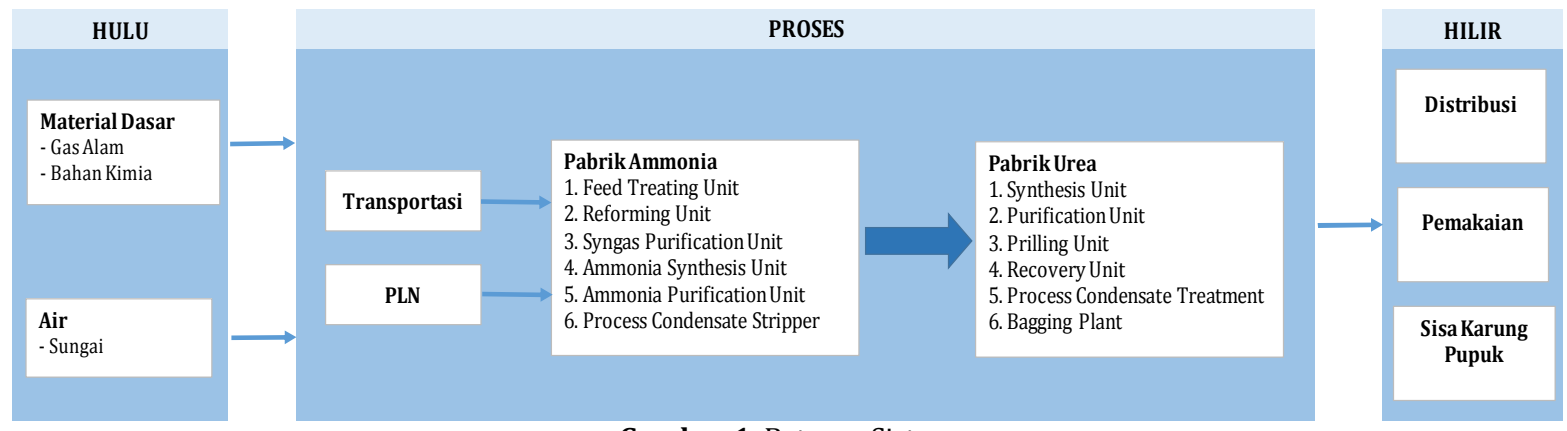

Gambar 1. Batasan Sistem

\section{Metode}

Kajian daur hidup (LCA) digunakan sebagai sebuah metode untuk identifikasi terhadap dampak lingkungan potensial dari sebuah proses produksi pupuk urea di PT Pupuk Kujang. Studi dibatasi pada Pabrik Kujang 1B yang memiliki kapasitas produksi 570.000 ton urea/tahun. Bahan baku utama dalam pembuatan pupuk urea adalah gas alam, air, dan udara yang diolah menjadi amoniak lalu diolah lanjut menjadi urea.

Metode mengacu kepada ISO 14040: 2006 tentang Life Cycle Assessment (LCA), dimana proses analisa terdiri dari empat bagian utama yaitu penentuan tujuan dan ruang lingkup, inventori daur hidup, dan kajian dampak daur hidup. Sedangkan tahapan yang terakhir adalah berupa interpretasi, dimana tahapan ini merupakan rangkuman analisa terhadap hasil kajian dampak dari tahapan sebelumnya.

\subsection{Tujuan dan lingkup}

Tujuan dari studi ini adalah untuk identifikasi terhadap dampak lingkungan potensial dan environmental hotspot dari operasi pabrik pupuk 
urea (Pabrik Kujang 1B). Fungsi unit yang digunakan adalah dampak lingkungan potensial dari produksi dan distribusi $50 \mathrm{~kg}$ pupuk urea.

Batasan sistem meliputi hulu, proses produksi, dan hilir (Gambar 1). Batasan hulu meliputi penggunaan material dasar, dan air. Sementara batasan proses produksi terdiri dari 2 (dua) bagian utama yang meliputi proses produksi ammonia, dan proses produksi urea. Pada bagian hilir memiliki batasan yang terdiri dari distribusi, pemakaian, dan pembuangan sisa karung.

\subsection{Inventori daur hidup}

Inventori daur hidup mempertimbangkan input dan ouput dari sebuah produk/proses sepanjang daur hidup nya (ISO, 2006). Pada studi ini produk yang diacu adalah $50 \mathrm{~kg}$ pupuk urea.
Data inventori merupakan data primer dan sekunder yang di dapatkan dari departemen terkait di PT Pupuk Kujang. Data yang digunakan antara lain pemakaian gas alam, air, listrik (PLN), bahan kimia (katalis), dan transportasi.

\subsection{Kajian dampak daur hidup (LCIA)}

Dalam melakukan kajian dampak daur hidup menggunakan software SimaPro ver 8.5.2 dengan metoda analisa CML-IA yang memiliki 11 kategori dampak (mid-point impact category) sebagai berikut abiotic depletion dan abiotic depletion (fossil fuel), global warming (GWP100), ozone layer depletion, human toxicity, fresh water dan marine aquatic ecotoxicity, terrestrial ecotoxicity, photochemical oxidation, acidification, dan eutrophication.

Tabel 1. Data Inventori Daur Hidup

\begin{tabular}{|c|c|c|c|}
\hline Proses & Jenis Input & Jenis Output & Jumlah Output/tahun \\
\hline Pabrik Ammonia & & $\begin{array}{l}\text { Hot Ammonia } \\
\text { Cold Ammonia }\end{array}$ & $\begin{array}{l}307.422 \text { ton } \\
7.985 \text { ton }\end{array}$ \\
\hline Feed Treating Unit & $\begin{array}{l}\text { Gas alam, air, katalis, } \\
\text { transportasi limbah }\end{array}$ & Treated natural gas & $210.427 .873 \mathrm{Nm}^{3}$ \\
\hline Reformig Unit & $\begin{array}{c}\text { Gas alam, syngas, listrik-PLN, } \\
\text { steam, katalis, transportasi } \\
\text { limbah }\end{array}$ & Synthesa gas & 1.108.943.022 $\mathrm{Nm}^{3}$ \\
\hline Syngas Purification Unit & $\begin{array}{l}\text { Syngas, listrik-PLN, katalis, } \\
\text { transportasi limbah }\end{array}$ & Treated synthesa gas & $984.096 .347 \mathrm{Nm}^{3}$ \\
\hline Ammonia Synthesis Unit & $\begin{array}{l}\text { Treated syngas, listrik-PLN, } \\
\text { steam, katalis, transportasi } \\
\text { limbah }\end{array}$ & Ammonia (konsentrasi 13\%) & $312.942 \mathrm{~m}^{3}$ \\
\hline Ammonia Purification Unit & Ammonia, listik-PLN, steam & Hot \& cold ammonia (konsentrasi 99,8\%) & 315.407 ton \\
\hline Process Condensate Stripper & $\begin{array}{l}\text { Condensate, listrik-PLN, } \\
\text { steam }\end{array}$ & Condensate & 388.396 ton \\
\hline Pabrik Urea & & Urea & 528.350 ton \\
\hline Synthesis Unit & $\begin{array}{c}\text { Ammonia, recycle gas, } \mathrm{CO}_{2}, \\
\text { steam, katalis }\end{array}$ & Urea solution (konsentrasi 49\%) & 1.109.454 ton \\
\hline Purification Unit & $\begin{array}{l}\text { Urea konsentrasi 49\%, off } \\
\text { gas, listrik-PLN, steam }\end{array}$ & Urea solution (konsentrasi 64\%) & 798.955 ton \\
\hline Concentration Unit & $\begin{array}{l}\text { Urea konsentrasi 64\%, } \\
\text { listrik-PLN, steam }\end{array}$ & Urea solution (konsentrasi 99,8\%) & 536.112 ton \\
\hline Prilling Unit & $\begin{array}{l}\text { Urea konsentrasi 99,8\%, } \\
\text { pewarna, anticaking, listrik- } \\
\text { PLN, steam, transportasi }\end{array}$ & Urea Prilled & 533.829 ton \\
\hline Recovery Unit & $\begin{array}{l}\text { Off gas, condensate, listrik- } \\
\text { PLN, steam }\end{array}$ & Carbamat Solution & 415.354 ton \\
\hline Process Condensate Treatment & $\begin{array}{l}\text { Process condensate, listrik- } \\
\text { PLN, steam }\end{array}$ & $\begin{array}{l}\text { Off Gas } \\
\text { Treated Condensate ke Prilling } \\
\text { Treated Condensate ke Utility }\end{array}$ & $\begin{array}{l}71.288 \text { ton } \\
3.240 \text { ton } \\
7.315 \text { ton }\end{array}$ \\
\hline Bagging Plant & $\begin{array}{l}\text { Urea prilling, listrik-PLN, } \\
\text { karung } 50 \mathrm{~kg} \text {, transportasi }\end{array}$ & Urea dalam karung $50 \mathrm{Kg}$ & 528.350 ton \\
\hline Distribusi & Transportasi, listrik-PLN & Pengiriman ke distributor dan kios & 63.917 ton \\
\hline Pemakaian & $\begin{array}{l}\text { Transportasi, pemanfaatan } \\
\text { limbah }\end{array}$ & Jumlah ammonia & 63.917 ton \\
\hline Pembuangan Sisa Karung & Transportasi, jumlah limbah & Jumlah karung & 76 ton \\
\hline
\end{tabular}

\section{Hasil dan Pembahasan}

\subsection{Analisa inventori daur hidup}

Pada inventori daur hidup dilakukan pengumpulan data yang berkaitan dengan masukan material (input) dan luaran material (output) serta emisi yang dikeluarkan oleh proses hulu, proses utama, dan proses hilir dari batasan sistim produksi urea. Sebagai salah satu ilustrasi, pada kebutuhan dasar Feed Treating Unit (FTU) membutuhkan gas 524 alam sebesar 7.589.577 MMBTU dan beberapa komponen lain seperti karbon aktif, cobalt molybdenum, zink oxide akan menghasilkan luaran (output) berupa gas alam olahan (treated natural gas) sebesar 210.427.873 $\mathrm{Nm}^{3}$ (Tabel 1). Dengan penggunaan material dan proses produksi ammonia maka pabrik ammonia akan menghasilkan luaran (output) sebesar 307.422 ton ammonia panas (hot 
ammonia) per tahun dan 7.985 ton ammonia dingin (cold ammonia) per tahun.

Luaran berupa ammonia akan menjadi masukan (input) pada pabrik urea, dimana pabrik urea membutuhkan ammonia sebesar 307.422 ton per tahun untuk menghasilkan urea sejumlah 528.350 ton pertahun. Pupuk dalam kemasan $50 \mathrm{Kg}$ yang merupakan produk dari Bagging Plant selanjutkan didistribusikan ke gudang distribusi di wilayah Indramayu sebesar 63.917 ton/tahun.

\subsection{Analisa dampak daur hidup}

Pada sub-bab analisa daur hidup akan membahas dua bagian utama yaitu sub-bab 3.2.1 akan membahas dampak daur hidup pupuk urea dari hulu (material dasar), proses produksi, hingga penimbunan sisa kemasan pupuk ke landfill. Hal ini mengacu pada batasan sistim cradle to grave.

Selanjutnya sub-bab 3.2.2 akan membahas environmental hotspots dari daur hidup urea, hal ini akan membantu dalam mengidentifikasi sumber masukan (input) yang memberikan konstribusi dampak terbesar.

\subsubsection{Dampak daur hidup pupuk urea}

Dari hasil analisa dampak daur hidup pupuk urea selama 1 tahun pada Tabel 2 terlihat bahwa proses produksi memberikan kontribusi dampak paling besar dibandingkan dengan pengelolaan limbah sisa karung (landfill). Proses produksi memberikan kontribusi dampak pada kisaran 99,14 - 100 persen dari total dampak yang di hasilkan, misalnya kategori dampak Pemanasan Global (GWP100) menunjukkan bahwa proses produksi memberikan kontribusi dampak sebesar 52,4 juta kg $\mathrm{CO}_{2}$-eq dan pengelolaan limbah sisa karung berkontribusi 591 ribu kg CO 2 -eq selama setahun.

Lebih lanjut, kajian dampak daur hidup terhadap proses produksi yang terdiri dari tiga bagian utama yaitu produksi ammonia, produksi urea, dan distribusi urea dalam kemasan $50 \mathrm{~kg}$ ditampilkan pada Tabel 3. Dari hasil analisa terlihat bahwa proses produksi ammonia memberikan kontribusi dampak yang lebih besar dibandingkan dengan dua proses lainnya yaitu proses produksi urea, dan distribusi. Pada Gambar 2 memperlihatkan perbandingan beberapa dampak daur hidup terhadap ketiga proses produksi. Terlihat bahwa dampak yang ditimbulkan pada proses di pabrik ammonia akan memberikan kontribusi lebih besar pada kisaran 22-37 persen lebih besar dibandingkan dengan proses di pabrik urea. Salah satu contoh terlihat pada kategori dampak pemanasan global (GWP100) terlihat bahwa proses di pabrik ammonia akan menghasilkan 8,24 kg CO 2 -eq per $50 \mathrm{~kg}$, sedangkan pabrik urea akan memberikan kontribusi GWP sebesar 4,73 kg CO 2 -eq per $50 \mathrm{~kg}$. Dengan kata lain bahwa pabrik ammonia memberikan kontribusi dampak 23,61 persen lebih besar dibandingkan pabrik urea.

Tabel 2. Hasil Kajian Dampak Daur Hidup (SimaPro ver 8.5.2)

\begin{tabular}{|c|c|c|c|c|c|c|}
\hline Kategori Dampak & Satuan & Total & Produk Urea & $\begin{array}{c}\text { Prosentase } \\
(\%)\end{array}$ & $\begin{array}{c}\text { Landfill } \\
\text { Scenario }\end{array}$ & $\begin{array}{c}\text { Prosentase } \\
(\%)\end{array}$ \\
\hline Abiotic depletion & $\mathrm{kg} \mathrm{Sb} \mathrm{eq}$ & 328,76 & 328,76 & 100 & - & - \\
\hline Abiotic depletion (fossil fuels) & MJ & $4.954 .068 .936,87$ & $4,946,501,781.76$ & 99,85 & $7.567 .155,11$ & 0,15 \\
\hline Global warming (GWP100a) & $\mathrm{kg} \mathrm{CO} 2 \mathrm{eq}$ & $53.009 .852,39$ & $52.418 .226,79$ & 98,88 & $591.625,60$ & 1,12 \\
\hline Ozone layer depletion (ODP) & kg CFC-11 eq & 27,12 & 27,12 & 100 & - & - \\
\hline Human toxicity & kg 1,4-DB eq & $58.596 .480,13$ & $58.130 .039,32$ & 99,20 & $466.440,81$ & 0,80 \\
\hline Fresh water aquatic ecotox. & kg 1,4-DB eq & 39.088.690,81 & $38.922 .799,91$ & 99,58 & $165.890,90$ & 0,42 \\
\hline Marine aquatic ecotoxicity & $\mathrm{kg} 1,4-\mathrm{DB}$ eq & $1,12 \mathrm{E}+11$ & $1,11 \mathrm{E}+11$ & 99,44 & $627.799 .036,21$ & 0,56 \\
\hline Terrestrial ecotoxicity & kg 1,4-DB eq & $54.757,88$ & $54.738,80$ & 99,97 & 19,08 & 0,03 \\
\hline Photochemical oxidation & $\mathrm{kg} \mathrm{C} 2 \mathrm{H} 4 \mathrm{eq}$ & $24.401,97$ & $24.275,76$ & 99,48 & 126,21 & 0,52 \\
\hline Acidification & $\mathrm{kg} \mathrm{SO} 2 \mathrm{eq}$ & $334.418,60$ & $331.537,44$ & 99,14 & $2.880,73$ & 0,86 \\
\hline Eutrophication & kg PO4--- eq & $170.252,84$ & $169.707,57$ & 99,68 & 545,27 & 0,32 \\
\hline
\end{tabular}

\subsubsection{Environmental Hotspot}

Kajian terhadap environmental hotspot akan memberikan gambaran terhadap tahapan atau proses kegiatan yang memberikan kontribusi terhadap dampak lingkungan.

Dari hasil analisa dengan memanfaatkan grafik jaringan (networking graph) pada program SimaPro terlihat bahwa sumber utama penghasil dampak disebabkan oleh penggunaan gas alam, katalis molybdenum, penggunaan listrik dari Perusahaan Listrik Negara (PLN), penggunaan polypropylene dalam material karung, dan transportasi. Penggunaan gas alam dengan volume kurang lebih 7,6 juta MMBTU telah memberikan kontribusi yang cukup besar terhadap beberapa kategori dampak yaitu pemanasan 
global (GWP), ozone depletion, terrestrial ecotoxicity, photochemical oxidation, dan acidification.

Sedangkan penggunaan katalis molybdenum akan memberikan kontribusi dampak terhadap parameter abiotic depletion, human toxicity, fresh water dan marine aquatic ecotoxicity.
Dari kajian dampak daur hidup terlihat bahwa produksi pupuk urea di PT Pupuk Kujang berkontribusi terhadap sejumlah parameter dampak yang dipengaruhi berbagai faktor baik internal maupun eksternal. Pengelolaan terhadap kedua faktor tersebut tentunya akan mampu meningkatkan kinerja PT Pupuk Kujang dari aspek kajian daur hidup (LCA).

Tabel 3. Hasil Kajian Dampak Daur Hidup Proses Produksi 50 Kg Urea

\begin{tabular}{llrrr}
\hline \hline Kategori Dampak & \multicolumn{1}{c}{ Satuan } & Urea & Ammonia & Distribusi \\
\hline Abiotic depletion & kg Sb eq & 0,00003 & 0,00007 & 0,000001 \\
Abiotic depletion (fossil fuels) & MJ & 464,78 & $1.014,49$ & 27,54 \\
Global warming (GWP100a) & kg CO2 eq & 4,73 & 8,24 & 1,92 \\
Ozone layer depletion (ODP) & kg CFC-11 eq & 0,000003 & 0,00001 & 0,0000001 \\
Human toxicity & kg 1,4-DB eq & 5,37 & 10,96 & 1,11 \\
Fresh water aquatic ecotox. & kg 1,4-DB eq & 3,55 & 6,64 & 1,09 \\
Marine aquatic ecotoxicity & kg 1,4-DB eq & $10.237,17$ & $19.405,73$ & $2.988,07$ \\
Terrestrial ecotoxicity & kg 1,4-DB eq & 0,005 & 0,01 & 0,002 \\
Photochemical oxidation & kg C2H4 eq & 0,002 & 0,005 & 0,0004 \\
Acidification & kg SO2 eq & 0,03 & 0,06 & 0,01 \\
Eutrophication & kg PO4--- eq & 0,02 & 0,03 & 0,01 \\
\hline
\end{tabular}


Gambar 2. Perbandingan Dampak Daur Hidup

\section{Kesimpulan}

Kajian daur hidup merupakan salah satu alat yang bisa digunakan untuk menganalisa kinerja lingkungan pada sebuah proses produksi termasuk proses produksi pupuk. PT Pupuk Kujang selaku salah satu produsen pupuk di Indonesia memiliki komitmen untuk melakukan kajian daur hidup terhadap proses produksi hingga pengelolaan limbah karung yang saat ini dilakukan.

Hasil dari kajian daur hidup menunjukkan bahwa proses produksi merupakan kontributor terbesar terhadap dampak lingkungan berdasarkan 11 (sebelas) parameter yang tertuang di metode CML-IA. Dari proses produksi maka produksi ammonia memiliki pengaruh yang paling besar terhadap dampak yang dihasilkan dibandingkan dengan proses produksi urea maupun transportasi urea. Dalam proses produksi ammonia ditemukan dua environmental hotspot utama yaitu penggunaan gas alam, dan katalis molybdenum. Selain itu environmental hotspots lainnya adalah penggunaan listrik dari PLN, penggunaan polypropylene, dan transportasi.

Dari hasil kajian dampak daur hidup maka peningkatan kinerja lingkungan atau perbaikan berkelanjutan yang dapat dilakukan oleh PT Pupuk Kujang adalah melakukan audit energi, dan manajemen pengelolaan penggunaan katalis.

\section{DAFTAR PUSTAKA}

FAO. 2017. "World Fertilizer Trends and Outlook to 2020." Rome.

Firmansyah, Imam, and Muhammad Syakir. 2017. "Pengaruh Kombinasi Dosis Pupuk N , P , Dan K Terhadap Pertumbuhan Dan Hasil Tanaman Terung ( Solanum Melongena L . ) [ The Influence of Dose Combination Fertilizer N, P , and K." J. Hort 27 (1): 6978.

Hasler, K, S Broering, S.W.F Omta, and H.W. Olfs. 2015. "Life Cycle Assessment (LCA) of Different Fertilizer Product Types." European Journal of Agronomy 69: 41-51.

https://doi.org/https://doi.org/10.1016/j.eja.2015. 06.001 .

Kemenperin. 2019. "Konsumsi Pupuk Kian Menanjak." 
Kementerian Perindustrian Republik Indonesia. 2019.

https://kemenperin.go.id/artikel/20500/KonsumsiPupuk-Kian-Menanjak.

Quiros, R., G. Villalba, X. Gabarrell, and P. Munoz. 2015. “Life Cycle Assessment of Organic and Mineral Fertilizers in a Crop Sequence of Cauliflower and Tomato." Int.J.Environ.Sci.Technol 12: 3299-3316. https://doi.org/10.1007/s13762-015-0756-7.

Romeiko, Xiaobo Xue. 2019. "A Comparative Life Cycle Assessment of Crop Systems Irrigated with the Groundwater and Reclaimed Water in Northern China." Sustainability 11 (2743): 1-17.
Skowroñska, Monika, and Tadeusz Filipek. 2014. "Life Cycle Assessment of Fertilizers : A Review.” International Agrophysics 28: 101-10. https://doi.org/10.2478/intag-2013-0032.

Vera-Acevedo, Luz Dinora, Johan Andrés Vélez-Henao, and Natalia Marulanda-Grisales. 2016. "Assessment of the Environmental Impact of Three Types of Fertilizers on the Cultivation of Coffee at the Las Delicias Indigenous Reservation ( Cauca )." Revista Facultad de Ingeniería, no. 80: 93-101. https://doi.org/10.17533/udea.redin.n81a09. 